\title{
Blood Pressure Percentiles in Turkish Children and Adolescents
}

\author{
(1) Ahmet Keskinoğlu1, (1) Pembe Keskinoglu22, (1) Su Özgür3, (1) Timur Köse3 \\ ${ }^{1}$ Ege University Faculty of Medicine, Department of Pediatric Nephrology, İzmir, Turkey \\ ${ }^{2}$ Dokuz Eylül University Faculty of Medicine, Department of Biostatistics and Medical Informatics, İzmir, Turkey \\ ${ }^{3}$ Ege University Faculty of Medicine, Department of Biostatistics and Medical Informatics, İzmir, Turkey
}

\begin{abstract}
Aim: Pediatric hypertension, a public health concern, is now commonly known worldwide to be an early risk factor for cardiovascular and renal morbidity and mortality. Early detection of hypertension is of the utmost importance to help reduce serious complications. Several distributions of country-specific blood pressure (BP) percentiles have been established worldwide. The aim of this study is to determine BP percentiles in healthy Turkish children aged 2 to 18 years.
\end{abstract}

Materials and Methods: In this cross-sectional study, BP was measured in 4,984 randomly selected children and adolescents aged 2-17 years. The $50^{\text {th }}, 90^{\text {th }}$ and $95^{\text {th }}$ percentile of BP percentiles were determined for gender, age and height with the use a polynomial regression model. BP percentiles at median height were compared with the US Fourth Report references.

Results: The normative values of systolic blood pressure (SBP) and diastolic blood pressure (DBP) increased with age for both genders and varied by gender. At median height, the age-specific differences at the $90^{\text {th }}$ percentile of SBP tended to be higher in boys than in girls at all ages. DBP values in girls were higher than in boys until the age of 9 years, after which boys demonstrated higher values compared to girls.

Conclusion: The age and height specific reference BP values determined in this study is a novel reference for Turkish children and adolescents. Turkish BP values are lower than existing US reference values.

Keywords: Blood pressure percentiles, children, height Z-score

\section{Introduction}

Pediatric hypertension, a public health concern, is now commonly known worldwide to be an early risk factor for cardiovascular and renal morbidity and mortality. Children with higher blood pressure (BP) are more likely to become hypertensive adults (1). Measuring BP is a part of physical examination in pediatric clinical practice and its significance had not been understood until recently. Since early detection of hypertension is of the utmost importance to help reduce various complications, BP assessment is now considered as an essential part of routine physical examination above 3 years of age (2). Elevated BP in children and adolescents is usually defined based on the distribution of $B P$ in a reference population. The BP percentiles used in adults to define hypertension (>140/90 $\mathrm{mmHg}$ ) is not applicable in the pediatric age group because BP is affected by age, gender and height in children (3).

BP percentile curves were first published in 1987 and described age specific distributions of systolic blood pressure (SBP) and diastolic blood pressure (DBP) for 
an age range between 5 and 17 years, with corrections for height and weight (4). An updated Report from the task force, published in 1996, provided additional details in infants and children (5). In 2004, the Fourth Report added further information including data for overweight and obese children and adapted data to growth charts previously developed by the Centers for Disease Control and Prevention (6). The inclusion of overweight and/or obese children in the normative BP values might lead to values as high as those that are used to define higher than normal BP in adults being considered as normal BP for children. The reference values of the Fourth Report are widely used in the US and European countries. In the Fourth Report, normal BP was defined as SBP and DBP values $<90^{\text {th }}$ percentile (on the basis of age, gender and height percentiles). For the preadolescent, prehypertension was defined as SBP and DBP $\geq 90^{\text {th }}$ percentile and $<95^{\text {th }}$ percentile. Hypertension was defined as SBP and DBP $\geq 95^{\text {th }}$ percentile (6). However, definitions of BP categories and stages have been updated in the new guideline of American Academy of Pediatrics for high BP in children and adolescents (7).

The BP values in children show diversity according to countries and, therefore many countries have begun to publish their own reference tables based on their population (8-14). The pooled BP reference values of six European studies have shown relatively high BP in comparison to US children (15).

A study conducted in Italy reported that the normal BP values in Italian children and adolescents were lower than US children and children in other European countries (8). The height-specific BP reference values for non-overweight Chinese children are lower than US reference values (16).

The BP reference values in Turkish children were conducted nearly 15 years ago (17). As secular trends of growing children will affect the normative values of BP, BP reference values should be updated. The aim of this study is to determine BP percentiles in healthy Turkish children aged 2 to 18 years.

\section{Materials and Methods}

This cross-sectional study was performed in 10 schools and nurseries (4 nurseries, 4 elementary schools and 2 high schools) in the selected urban location of Izmir in Turkey with a population of 73,908 individuals aged 2 to17 years between 2012-2013. The population in this region has low and/or fair socio-economic status. A stratified random cluster sampling method was used to select the children. The minimum sample size was calculated as 3,456 children.
A total of 5,417 children were enrolled, with a response rate of $92 \%$ (4,984 children). The children were healthy with no acute or chronic diseases. All measurements were performed by physicians and trained nurses. Weight to the nearest 0.1 $\mathrm{kg}$ and height to the nearest $0.1 \mathrm{~cm}$ were measured using a Calibrated Electronic scale (SECA, Birmingham, United Kingdom) and a Stadiometer (Harpender stadiometer; Holtain Ltd, Crymych, United Kingdom). BP was measured with an oscillometric device using the right arm at the level of the heart and choosing a proper cuff size, which had to cover $80 \%-100 \%$ of the arm circumference and width of approximately $40 \%$ of the arm length. After at least 5 minutes of rest in the sitting position, three readings of BP for each child were taken with an interval of 2 minutes between readings. Korotkoff phase 1 and Korotkoff phase 5 were used for defining SBP and DBP (12).

The average of the three measurements was used for the analysis. Body Mass index was calculated as the ratio of weight $(\mathrm{kg})$ by height squared $\left(\mathrm{m}^{2}\right)$. We used the US Fourth Report as the source for all threshold values (6).

The study was approved by the Ethical Committee of Ege University and by the provincial education directorate. Informed written consent was obtained from all parents and from those adolescents aged 13 years and older.

\section{Statistical Analysis}

The polynomial regression model was applied to estimate BP percentiles in relation to gender, age and height by the equation via R version 3.0.2.

$B P_{i}=\sum_{j=1}^{4} \beta_{j}\left(\text { age }_{i}-10\right)^{j}+\sum_{k=1}^{4} \gamma_{k}\left(\text { Zheight }_{i}\right)^{k}+\sum_{k=1}^{4} \gamma_{k}\left(\text { Zweight }_{i}\right)^{k}+e_{i}$

A fourth-degree polynomial model was used to predict adjusted BP as a function of age and height Z-score (Zht) for both sexes separately. In the second stage, BP percentiles were constructed after excluding overweight children $\left(>90^{\text {th }}\right.$ percentile) because of the possible influence of excess weight on BP distribution, and BP nomogram were refined using the normative database of non-overweight children using the equation.

$B P_{i}=\sum_{j=1}^{4} \beta_{j}\left(\text { age }_{i}-10\right)^{j}+\sum_{k=1}^{4} \gamma_{k}\left(\text { Zheight }_{i}\right)^{k}+e_{i}$

\section{Results}

The study population consisted of 2,498 (50.1\%) boys and $2,486(49.1 \%)$ girls. We found that the values of SBP 
and DBP increased with age for both genders and varied by gender. At median height, the age-specific differences in the $90^{\text {th }}$ percentile of SBP tended to be higher in boys than in girls at all ages. The differences of SBP ranged from 0 to $3 \mathrm{mmHg}$ until the age of 13 years and ranged from 2 to $7 \mathrm{mmHg}$ for individuals $>13$ years old. However, the DBP percentile in boys was higher than in girls by up to 2-4 $\mathrm{mmHg}$ in the age group of 2-3 years, after which girls demonstrated higher values by up to $1-3 \mathrm{mmHg}$ compared to boys between the ages of 4-8 years. DBP percentiles were higher in boys after 8 years old by up to $1-65 \mathrm{mmHg}$.

Table I and Table II shows the corresponding age- and height-specific SBP and DBP percentile values in boys and girls.

Figure 1 and 2 shows the $90^{\text {th }}$ percentile of SBP and DBP in boys and in girls by age and percentile of height (height Z-score).

\section{Discussion}

The present study provides normative age and heightspecific SBP and DBP values in Turkish children in the age range 2-17 years. We used the same statistical method as the Fourth Report, and we created BP percentiles based on the reference values of the US references. The advantage of this model is that although the distribution of height varies greatly with age, the distribution of Zht does not. Different statistical methods are used to determine BP percentiles in children $(18,19)$.

We found that the SBP and DBP levels of the $90^{\text {th }}$ percentiles in Turkish children and adolescents are lower than the US Fourth Report BP references. At median height, the age specific differences in the $90^{\text {th }}$ percentiles for SBP in boys and girls were lower by up to $6-13 \mathrm{mmHg}$ and 6-11 $\mathrm{mmHg}$, respectively, and for DBP by up to 1-8 $\mathrm{mmHg}$ and 3-7 $\mathrm{mmHg}$, respectively compared with the US references. The present study also included overweight children, as did the Fourth Report. However, the percentage of the overweight children is low. We found that the BP reference values were not influenced by the prevalence of overweight children.

In a study carried out in eight European countries including children (overweight and non-overweight) aged 2 to 10.9 years, SBP and DBP percentiles in boys and girls were higher than our study population for the same age group (12).

In a national study from Turkey in children from birth to 18 years carried out in 1999, the mean SBP and DBP values showed similar values with the results reported in the study of the second task force with small difference (17).
The growth charts for boys and girls were updated in 2006 (20). Therefore, new BP curves for both genders in Turkish children should be determined.

According to data on BP from seven large nationally representative cross-sectional surveys in children aged 6-17 years of age in China, India, Iran, Korea, Poland, Tunisia, and USA published by Xi et al. (14), SBP and DBP reference values in boys and girls from a similar age group were higher than those the present study. The difference between BP percentiles may be due, in part, to the fact that $\mathrm{Xi}$ et al. (14) study excluded overweight/obese children while our study included overweight children. In addition, different statistical models were used for these two studies. The authors found similar BP percentiles to the revised US Fourth Report.

In German children, the normal-weight percentiles are nearly identical with the overall growth charts. However, at the $90^{\text {th }}$ percentile, the authors found among 17-yearold adolescents $1 / 1 \mathrm{mmHg}$ higher values in overall than in normal-weight males and females corresponding with $1 / 1$ $\mathrm{mmHg}$ in male and $1 / 3 \mathrm{mmHg}$ in females US adolescents (21). The authors found very small differences between normal-weight German and US children. This suggests that separate growth charts for normal-weight youths are not necessary. The comparison of the overall percentiles from the United States, Poland and Germany demonstrates very similar values $(21,22)$.

A study conducted in Tehran by Ataei et al. (23) compared the $95^{\text {th }}$ percentile of BP values of surveys from seven countries including Turkey. The SBP rose progressively with age in both genders, with the rise being steeper among boys after the age of 13. The DBP curves show slight differences between the two genders. British and Saudi Arabian children present the highest SBP levels for both genders compared to other countries with minor differences compared to each other until the age of 13 , where their curves start to diverge and the data from the UK remains higher. Up to the age of six, Iran has the lowest BP levels among these countries for both genders. Saudi Arabia has the highest levels in almost all ages for both genders, while the Iranian DBP curve presents the lowest DBP levels. British DBP levels present with a mostly horizontal line until it becomes the lowest after the age of 13 years.

Raj et al. (24) reported that the BP normative values in Indian children aged 5-16 years demonstrated a different pattern in comparison to the US data. BP percentiles of Indian schoolchildren have higher DBPs for both genders than the Fourth Report reference. For SBP, girls showed 


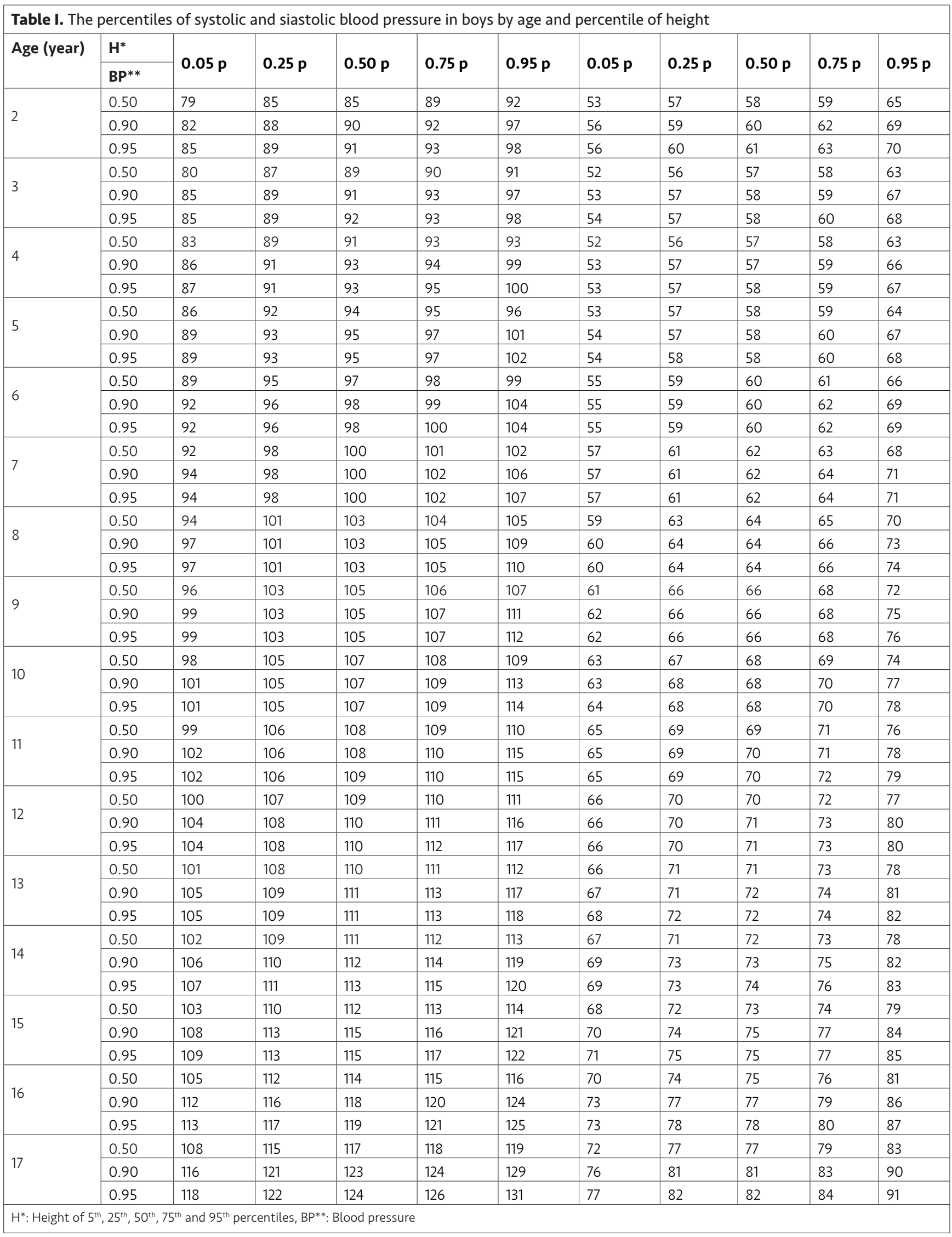


Table II. The percentiles of systolic and diastolic blood pressure in girls by age and percentile of height

\begin{tabular}{|c|c|c|c|c|c|c|c|c|c|c|c|}
\hline \multirow{3}{*}{$\begin{array}{l}\text { Age } \\
\text { (year) }\end{array}$} & \multirow{3}{*}{$\begin{array}{l}\mathbf{H}^{*} \\
\mathbf{B P}^{* *}\end{array}$} & \multicolumn{5}{|l|}{ SBP } & \multicolumn{5}{|l|}{ DBP } \\
\hline & & \multirow{2}{*}{$0.05 p$} & \multirow{2}{*}{$0.25 \mathrm{p}$} & \multirow{2}{*}{$0.50 p$} & \multirow{2}{*}{$0.75 \mathrm{p}$} & \multirow{2}{*}{$0.95 p$} & \multirow{2}{*}{$0.05 p$} & \multirow{2}{*}{$0.25 p$} & \multirow{2}{*}{$0.50 p$} & \multirow{2}{*}{$0.75 \mathrm{p}$} & \multirow{2}{*}{$0.95 p$} \\
\hline & & & & & & & & & & & \\
\hline \multirow{3}{*}{2} & 0.50 & 81 & 82 & 84 & 87 & 91 & 50 & 51 & 53 & 55 & 58 \\
\hline & 0.90 & 83 & 86 & 87 & 89 & 95 & 52 & 54 & 56 & 58 & 62 \\
\hline & 0.95 & 84 & 87 & 88 & 90 & 96 & 53 & 55 & 57 & 59 & 63 \\
\hline \multirow{3}{*}{3} & 0.50 & 83 & 84 & 87 & 89 & 93 & 52 & 54 & 56 & 58 & 60 \\
\hline & 0.90 & 85 & 87 & 89 & 90 & 96 & 54 & 55 & 57 & 60 & 63 \\
\hline & 0.95 & 85 & 88 & 89 & 91 & 97 & 54 & 56 & 58 & 60 & 64 \\
\hline \multirow{3}{*}{4} & 0.50 & 86 & 87 & 89 & 92 & 96 & 54 & 56 & 58 & 60 & 63 \\
\hline & 0.90 & 87 & 89 & 91 & 92 & 98 & 55 & 57 & 59 & 61 & 65 \\
\hline & 0.95 & 87 & 90 & 91 & 93 & 99 & 55 & 57 & 59 & 62 & 65 \\
\hline \multirow{3}{*}{5} & 0.50 & 89 & 90 & 92 & 95 & 99 & 56 & 58 & 59 & 62 & 64 \\
\hline & 0.90 & 89 & 92 & 93 & 95 & 101 & 56 & 58 & 60 & 63 & 66 \\
\hline & 0.95 & 89 & 92 & 93 & 95 & 101 & 57 & 58 & 60 & 63 & 67 \\
\hline 6 & 0.50 & 92 & 93 & 95 & 98 & 102 & 57 & 59 & 61 & 63 & 66 \\
\hline 6 & 0.90 & 92 & 95 & 96 & 97 & 104 & 58 & 59 & 61 & 64 & 67 \\
\hline & 0.95 & 92 & 95 & 96 & 98 & 104 & 58 & 60 & 62 & 64 & 68 \\
\hline & 0.50 & 95 & 96 & 98 & 101 & 105 & 59 & 60 & 62 & 64 & 67 \\
\hline 7 & 0.90 & 95 & 97 & 99 & 100 & 106 & 59 & 61 & 63 & 65 & 68 \\
\hline & 0.95 & 95 & 97 & 99 & 100 & 107 & 59 & 61 & 63 & 65 & 69 \\
\hline 8 & 0.50 & 97 & 99 & 101 & 104 & 107 & 60 & 61 & 63 & 65 & 68 \\
\hline 8 & 0.90 & 97 & 100 & 101 & 103 & 109 & 60 & 62 & 64 & 66 & 70 \\
\hline & 0.95 & 97 & 100 & 101 & 103 & 109 & 60 & 62 & 64 & 66 & 70 \\
\hline & 0.50 & 99 & 101 & 103 & 106 & 110 & 61 & 62 & 64 & 66 & 69 \\
\hline 9 & 0.90 & 99 & 102 & 103 & 105 & 111 & 61 & 63 & 65 & 67 & 70 \\
\hline & 0.95 & 99 & 102 & 103 & 105 & 111 & 61 & 63 & 65 & 67 & 71 \\
\hline & 0.50 & 101 & 103 & 105 & 108 & 111 & 62 & 63 & 65 & 67 & 70 \\
\hline 10 & 0.90 & 101 & 104 & 105 & 107 & 113 & 62 & 63 & 65 & 68 & 71 \\
\hline & 0.95 & 101 & 104 & 105 & 107 & 113 & 62 & 63 & 66 & 68 & 72 \\
\hline & 0.50 & 103 & 104 & 106 & 109 & 113 & 62 & 64 & 66 & 68 & 71 \\
\hline 11 & 0.90 & 103 & 105 & 107 & 108 & 114 & 63 & 64 & 66 & 69 & 72 \\
\hline & 0.95 & 103 & 106 & 107 & 108 & 115 & 63 & 64 & 66 & 69 & 73 \\
\hline & 0.50 & 103 & 105 & 107 & 110 & 114 & 63 & 65 & 66 & 69 & 71 \\
\hline 12 & 0.90 & 104 & 107 & 108 & 109 & 116 & 63 & 65 & 67 & 69 & 73 \\
\hline & 0.95 & 104 & 107 & 108 & 110 & 116 & 64 & 65 & 67 & 70 & 73 \\
\hline & 0.50 & 104 & 106 & 108 & 110 & 114 & 64 & 65 & 67 & 69 & 72 \\
\hline 13 & 0.90 & 105 & 108 & 109 & 110 & 117 & 64 & 66 & 68 & 70 & 74 \\
\hline & 0.95 & 105 & 108 & 109 & 111 & 117 & 65 & 66 & 68 & 71 & 75 \\
\hline & 0.50 & 105 & 106 & 108 & 111 & 115 & 64 & 66 & 68 & 70 & 73 \\
\hline 14 & 0.90 & 106 & 109 & 110 & 111 & 118 & 65 & 67 & 69 & 72 & 75 \\
\hline & 0.95 & 106 & 109 & 111 & 112 & 118 & 66 & 68 & 70 & 72 & 76 \\
\hline 15 & 0.50 & 105 & 106 & 109 & 111 & 115 & 65 & 66 & 68 & 70 & 73 \\
\hline 15 & 0.90 & 107 & 110 & 111 & 113 & 119 & 67 & 69 & 71 & 73 & 77 \\
\hline & 0.95 & 108 & 111 & 112 & 114 & 120 & 68 & 69 & 71 & 74 & 78 \\
\hline & 0.50 & 106 & 107 & 109 & 112 & 116 & 66 & 67 & 69 & 71 & 74 \\
\hline 16 & 0.90 & 109 & 112 & 113 & 115 & 121 & 69 & 71 & 73 & 75 & 78 \\
\hline & 0.95 & 110 & 113 & 114 & 116 & 122 & 70 & 72 & 74 & 76 & 80 \\
\hline & 0.50 & 107 & 108 & 110 & 113 & 117 & 67 & 68 & 70 & 72 & 75 \\
\hline 17 & 0.90 & 112 & 114 & 116 & 117 & 123 & 71 & 73 & 75 & 77 & 81 \\
\hline & 0.95 & 113 & 116 & 117 & 119 & 127 & 73 & 74 & 77 & 79 & 83 \\
\hline
\end{tabular}




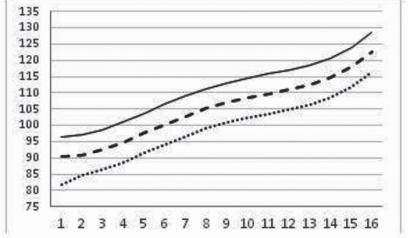

A

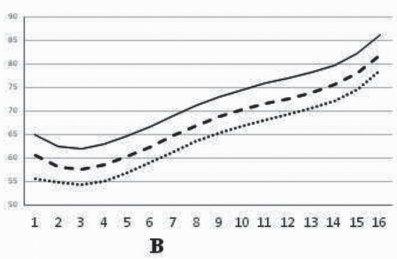

Figure 1. $90^{\text {th }}$ percentile of blood pressure in boys by age and percentile of height (height z score)

A. Systolic blood presure; B. Diastolic blood presure
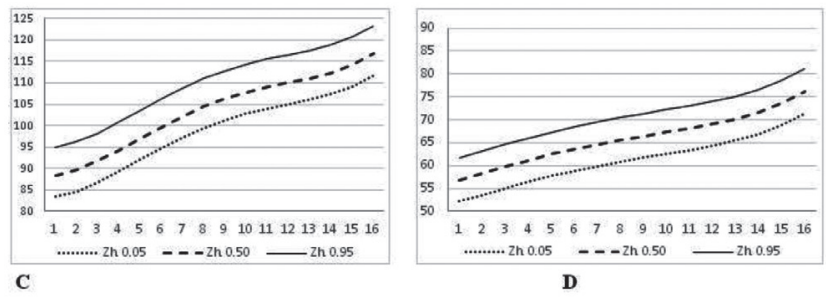

Figure 2. $90^{\text {th }}$ percentile of blood pressure in girls by age and percentile of height (height z-score)

C. Systolic blood presure; D. Diastolic blood presure

higher values than the Fourth Report reference, while for boys, the difference appears to be minimal.

A reference sample of Chinese children aged 7-17 years from the Chinese Health and National Survey 1991-2009 was compared with the Fourth Report references. The $50^{\text {th }}, 90^{\text {th }}$ and $95^{\text {th }}$ percentiles of SBP in boys and girls were on average 9-10 $\mathrm{mmHg}$ lower than their American counterparts; however, there were no clear differences in DBP percentiles. These results are consistent with the BP percentiles of our study (16). Whereas a national study obtained by the 2010 National Health Survey in children between 7-17 years of age from China reported that the $50^{\text {th }}$, $90^{\text {th }}, 95^{\text {th }}$ and $99^{\text {th }}$ percentiles of BP in boys and girls aged 7 to 13 years were consistent with the US reference (25).

Polish preschool children's $90^{\text {th }}$ and $95^{\text {th }}$ SBP and DBP percentiles were lower than those in the US and German $\mathrm{BP}$ references. Differences in the $95^{\text {th }} \mathrm{SBP}$ percentiles ranged by age from -5 to $0 \mathrm{mmHg}$ and from -2 to $-1 \mathrm{mmHg}$, in boys and girls, respectively, whereas the difference at the same percentile of DBP ranged from -7 to $-1 \mathrm{mmHg}$ and from -5 to $-1 \mathrm{mmHg}$ in boys and girls, respectively. However, the $90^{\text {th }}$ percentiles of SBP and DBP in Polish preschool children were higher than those for our children (22).

The comparison of data regarding $\mathrm{BP}$ percentiles in children from similar studies may be possibly limited by the different $\mathrm{BP}$ readings obtained from different automated devices, BP measurement numbers and different statistical methods used. BP normative values can also show differences depending on whether or not overweight children are included in the study. Furthermore, different patterns of BP percentiles in children and adolescents in different countries may be due to the influence of diverse socio-economic, cultural and nutritional factors in comparison to the US references.

\section{Study Limitations}

The present study has several limitations. Firstly, the reference values are based on BP measurements measured during a single session and not on multiple estimates from at least 3 separate sessions. Secondly, environmental factors were not included because life style data were not available for all subjects who took part in this study. Finally, comparable data from rural areas were not available. Therefore, the generalization of our results is limited.

\section{Conclusion}

We found that the values of SBP and DBP increased with age for both genders and varied by gender. The SBP and DBP levels of the $90^{\text {th }}$ percentiles in Turkish children and adolescents are lower than the US BP references. In contrast to the US Fourth Report references, the reference values of the present study are not influenced by the prevalence of overweight children. National BP reference values of Turkish children and adolescents will be useful for international comparisons of national normative BP values and for evaluating the prevalence of elevated BP in children.

\section{Acknowledgements}

This manuscript's content is a part of the MSc. thesis of 2nd author/; Pembe KESKINOĞLU (Thesis Number: 494672).

\section{Ethics}

Ethics Committee Approval: The study was approved by the Ethical Committee of Ege University and by the provincial education directorate (approval number: 11.12.2013, date: 12.01.2012).

Informed Consent: Informed written consent was obtained from all parents and from those adolescents aged 13 years and older.

Peer-review: Externally and internally peer-reviewed.

\section{Authorship Contributions}

Concept: A.K., P.K., T.K., Design: A.K., P.K., T.K., Data Collection or Processing: P.K., S.Ö., Analysis or Interpretation: A.K., P.K., S.Ö., T.K., Literature Search: A.K., P.K., S.Ö., T.K., Writing: T.K.

Conflict of Interest: None of the authors had conflict of interest. 
Financial Disclosure: The study founded by Ege University Unit of Scientific Research Projects (Project Number: 12-TIP-025).

\section{References}

1. Bao W, Threefoot SA, Srinivasan SR, Berenson CS. Essential hypertension predicted by tracking of elevated blood pressure from childhood to adulthood: the Bogalusa Heart Study. Am J Hypertens 1995; 8:657-65.

2. Somu S, Sundaram B, Kamalanathan A. Early detection of hypertension in general practice. Arch Dis Child 2003; 88:302.

3. Rosner B, Prineas RJ, Loggie JM, Daniels SR. Blood pressure nomograms for children and adolescents, by height, sex, and age, in the United States. J Pediatr 1993; 123:871-86.

4. Report of the Second Task Force on Blood Pressure Control in Children-1987. Task Force on Blood Pressure Control in Children. National Heart, Lung, and Blood Institute, Bethesda, Maryland. Pediatrics 1987; 79:1-25.

5. Update on the 1987 Task Force Report on High Blood Pressure in Children and Adolescents: a working group report from the National High Blood Pressure Education Program. National High Blood Pressure Education Program Working Group on Hypertension Control in Children and Adolescents. Pediatrics 1996; 9:649-58.

6. The fourth report on the diagnosis, evaluation and treatment of high blood pressure in children and adolescents. Pediatrics 2004; 114(2 Suppl):555-76.

7. Flynn JT, Kaelber DC, Baker-Smith CM, et al. Clinical practice guideline for screening and management of high blood pressure in children and adolescents. Pediatrics 2017; 140:20171904.

8. Menghetti $E$, Virdis $R$, Strambi $M$, et al. Blood pressure in childhood and adolescence: the Italian normal standards. Study Group on Hypertension of the Italian Society of Pediatrics. I Hypertens 1999; 17:1363-72.

9. Wühl E, Witte K, Soergel M, Mehls O, Schaefer F, German Working Group on Pediatric Hypertension. Distribution of 24-h ambulatory blood pressure in children: normalized reference values and role of body dimensions. I Hypertens 2002; 20:19952007.

10. Ayatollahi T, Zare M. Blood pressure standards for shiraz (southern Iran) school children in relation to height. Iran I Pediatr 2012; 22:223-30.

11. Wang Z, Ma J, Dong B, Song Y, Hu PJ, Zhang B. Comparison of blood pressure levels among four age groups of Chinese children matched by height. J Human Hypertens 2012; 26:43742.
12. Barba G, Buck C, Bammann K, et al. Blood pressure reference values for European non-overweight school children: the IDEFICS study. Int I Obes (Lond.) 2014; 38(Suppl 2):48-56.

13. Jiang X, Cao Z, Shen L, et al. Blood pressure tables for Chinese adolescents: justification for incorporation of important influencing factors of height, age and sex in the tables. BMC Pediatr 2014; 14:10.

14. Xi $B$, Zong $X$, Kelishadi $R$, et al. Establishing international blood pressure references among non overweight children and adolescents aged 6 to 17 years. Circulation 2016; 133:398-408.

15. de Man SA, Andre IL, Bachmann H), et al. Blood pressure in childhood: pooled findings of six European studies. ) Hypertens 1991; 9:109-14.

16. Yan W, Liu F, Li X, et al. Blood pressure percentiles by age and height for non-overweight Chinese children and adolescents: analysis of the China Health and Nutrition Surveys 1991-2009. BMC Pediatr 2013; 13:195.

17. Tümer $N$, Yalcinkaya $F$, Ince $E$, et al. Blood pressure nomograms for children and adolescent in Turkey. Pediatr Nephrol 1999; 13:438-43.

18. Rosner B, Cook N, Portman R, Daniels S, Falkner B. Determination of blood pressure percentiles in normal-weightchildren: some methodological issues. Am / Epidemiol 2008; 167:653-66.

19. Cole TJ, Green PJ. Smoothing reference centile curves: the LMS method and penalized likelihood. Stat Med 1992; 11:1305-19.

20. Neyzi O, Furman A, Bundak R, Gunoz H, Darendeliler F, Bas F. Growth references for Turkish children aged 6-18 years. Acta Paediatr 2006; 95:1635-41.

21. Schwandt P, Scholze JE, Bertsch T, Liepold E, Haas GM. Blood pressure percentiles in 22,051 German children and adolescents: the PEEP Family Heart Study. Am J Hypertension 2015; 28:672-9.

22. Krzyzaniak A, Krzywinska-Wiewiorowska M, StawinskaWitoszynska B, et al. Blood pressure references for Polish children and adolescents. Eur J Pediatr 2009; 168:1335-42.

23. Ataei $N$, Baikpour $M$, Hosseini $M$, et al. Blood pressure nomogram for children and adolescents by age and body mass index in Tehran Iran. Iran J Public Health 2017; 46:368-79.

24. Raj M, Sundaram R, Paul M, Kumar K. Blood pressure distribution in Indian children. Indian Pediatr 2010; 47:477-85.

25. Dong $\mathrm{Y}, \mathrm{Ma}$ ), Song $\mathrm{Y}$, et al. National blood pressure reference for Chinese han children and adolescents aged 7 to 17 years. Hypertension 2017; 70:897-906. 